\title{
CARACTERIZAÇÃO ESPECTRAL DE SOLOS DO MUNICÍPIO DE FEIRA DE SANTANA - BA
}

\section{Ramon Oliveira Santos ${ }^{1}$, Joselisa Maria Chaves $^{2}$}

1. Bolsista PIBIC/Fapesb, Graduando em Agronomia, Universidade Estadual de Feira de Santana, e-mail: osantos.ramon@gmail.com

3. Orientadora, Departamento de Ciências Exatas, Universidade Estadual de Feira de Santana, e-mail: joselisa@uefs.br

PALAVRAS-CHAVE: Espectrorradiometria, Solos, Geociências.

\section{INTRODUÇÃO}

O estudo de solos de uma região, nos dias atuais, tem um caráter essencial na preservação do ambiente, uma vez que entender suas propriedades, constituição e morfologia é requisito para a realização de um manejo adequado deste recurso natural (RESENDE et al., 2014). Assim, utilizar geotecnologias como o sensoriamento remoto para a realização de estudos ambientais é uma inovação que vem contribuindo para a obtenção de resultados satisfatórios.

A espectroscopia ou espectrorradiometria de reflectância é uma das principais técnicas de sensoriamento remoto que tem sido utilizada nos últimos anos para caracterização de diferentes alvos terrestres, tais como rochas, água, vegetação e solos (NOVO, 2008). Esta capta o fluxo de radiação de eletromagnética refletida por objetos, neste caso o solo, sem haver o contato físico entre o sensor e o alvo. Os valores de reflectância do objeto ao longo espectro eletromagnético define o seu comportamento espectral (BELLINASO, 2009).

A realização de análises espectrorradiométricas de amostras de solos visa caracterizar as curvas de reflectância geradas, descrevendo assim o seu comportamento espectral. A reflectância é determinada por espectrorradiômetros e pode ser representada por gráficos (SATO, 2015). Cada classe de solo possui uma determinada assinatura espectral, pois esta é alterada principalmente por fatores como teor de matéria orgânica, teor de ferro, composição mineralógica, teor de umidade e textura.

A área de estudo é o município de Feira de Santana, localizado a leste do estado da Bahia, entre a Zona da Mata e o Sertão, em uma zona de transição designada de Agreste Baiano. Os solos do município são Chernossolo, Planossolo, Latossolo vermelho amarelo, Argissolo vermelho amarelo e Neossolo (EMBRAPA/SUDENE, 1973). É constituído geologicamente por conglomerados/brechas, diatexitos, gnaisses charnockíticos, granitoides. A vegetação predominante engloba o contato caatingafloresta estacional e floresta estacional decidual. As unidades geomórficas são pediplano sertanejo, tabuleiros interioranos e tabuleiros pré-litorâneos (BAHIA, 2017).

O presente trabalhou buscou pesquisar o comportamento espectral de solos localizados nas áreas de olarias, que geralmente se encontram próximas a margem de lagoas e nascentes. Assim, o uso da espectrorradiometria para a caracterização espectral de solos é bastante relevante, pois essa técnica além de inovadora, não polui o meio ambiente e tem baixo custo, possibilitando assim o estudo dos solos de forma rápida e sustentável (CLARK, 1999).

\section{METODOLOGIA}

A presente pesquisa foi feita seguindo os métodos do plano de trabalho. Primeiramente, foi feita uma revisão bibliográfica dos materiais já produzidos nesta linha de pesquisa. Cerca de 15 artigos e 2 dissertações foram lidos, o que contribuiu para o desenvolvimento de argumentos técnicos e científicos abordados na pesquisa.

Em seguida, foi feito o campo para a coleta das amostras superficiais por pontos com auxílio de trado, na profundidade de $0-20 \mathrm{~cm}$, acondicionadas em sacos plásticos, devidamente identificadas e contendo as coordenadas geográficas (Tabela 1). Os dados 
foram coletados e georreferenciados com o uso do GPS de navegação (Garmin) com média de erro +/- 15m. Em seguida, os pontos amostrais foram plotados no mapa de solos do município através do software Arcgis (figura 1).

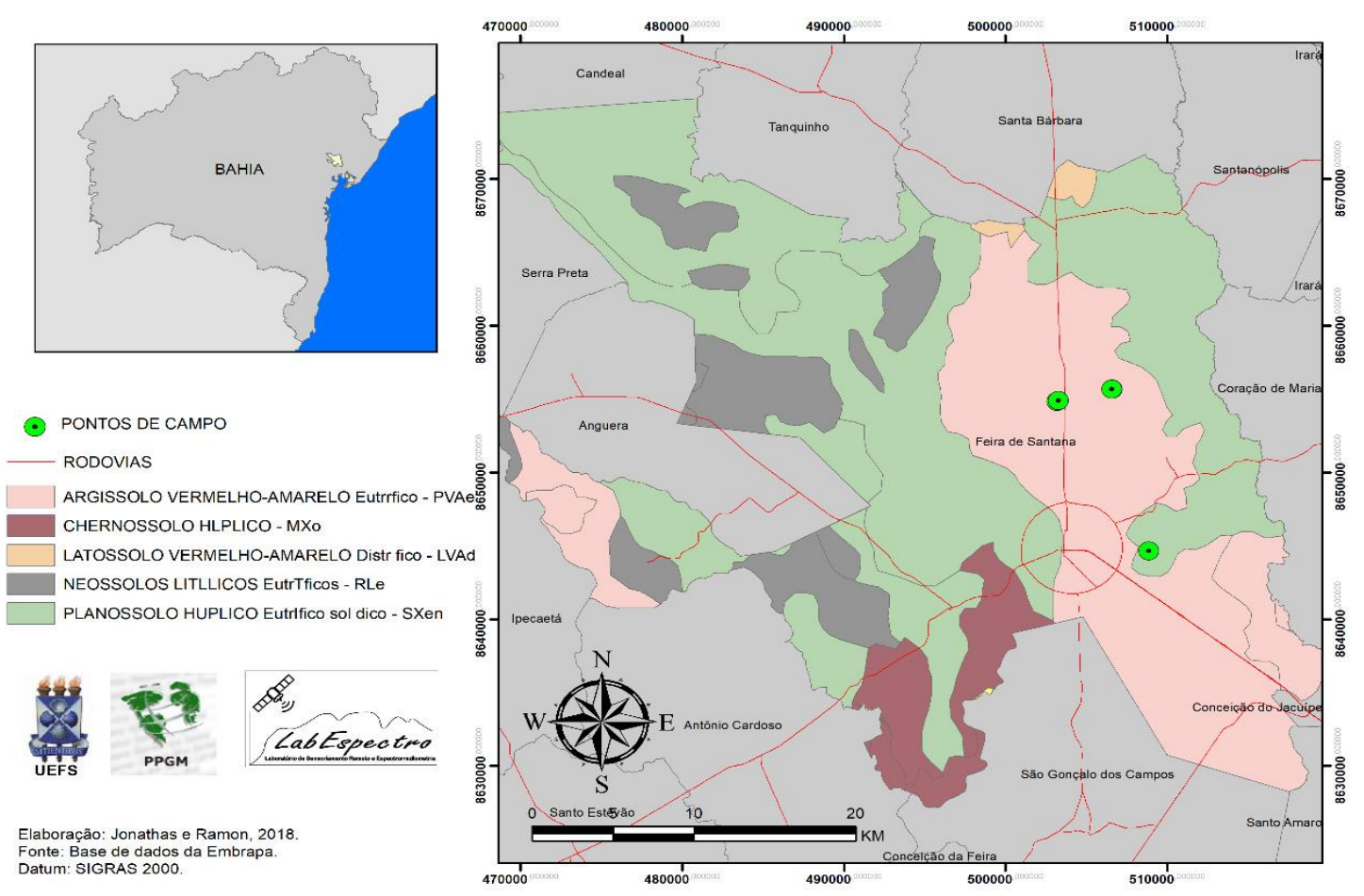

Figura 1. Mapa de localização dos pontos amostrais de Feira de Santana - BA

As amostras de solos foram preparadas para avaliação espectral no Laboratório de Espectrorradiometria (LABESPECTRO) do Programa de Pós-Graduação em Ciências da Terra e do ambiente (PPGM) da Universidade Estadual de Feira de Santana (UEFS). As amostras foram peneiradas em malha de $2 \mathrm{~mm}$ para homogeneizar seus efeitos de rugosidade e umidade, e secas em estufa a $45^{\circ} \mathrm{C}$, em um período de $24 \mathrm{~h}$, de acordo com a metodologia de Bellinaso (2009). Após este procedimento, as amostras foram alocadas em placa de petri de $13,5 \mathrm{~cm}$ de comprimento e armazenadas no LABESPECTRO.

A interpretação dos resultados foi realizada com apoio da pesquisa bibliográfica sobre bibliotecas espectrais e comportamento espectral de solos, fundamentada nos métodos aplicados por Epiphanio (1992) e Bellinaso (2009). Assim, foi feita uma análise visual das curvas espectrais obtidas, visando a identificação das regiões de absorção e seus valores, feições típicas dos componentes pedológicos que exercem forte influência no comportamento espectral.

\section{RESULTADOS E DISCUSSÃO}

A área selecionada para estudo encontra-se no município de Feira de Santana. Assim, a partir dos dados de campo e dos dados oriundos do mapa de solos da base de dados da Embrapa, constatou-se que os pontos 1 a 4 pertencem à classe de solo do tipo Argissolo vermelho-amarelo e o ponto 5 à classe do tipo Planossolo Háplico (tabela 1). Com a descrição do comportamento espectral dos pontos amostrais (figura 2) pode-se então estabelecer relações entre as feições da curva, mineralogia, características físicas do solo, tipo de solo e análise da fertilidade. Além disso, na espectrorradiometria de reflectância tem-se uma unidade de análise pequena (amostra de solo), logo a curva 
espectral obtida tem mais detalhes, já que entre a amostra e o aparelho não existe absorção da água pela atmosfera (SANTOS, CHAVES, 2016).

Tabela 1. Dados de campo

\begin{tabular}{|c|c|c|c|c|c|c|}
\hline \multirow[t]{2}{*}{ Ponto } & \multirow{2}{*}{$\begin{array}{l}\text { Nome da } \\
\text { amostra }\end{array}$} & \multirow[t]{2}{*}{ Nome da classe } & \multirow[t]{2}{*}{ Sigla } & \multicolumn{3}{|c|}{ Coordenadas } \\
\hline & & & & $\mathrm{X}$ & $\mathrm{Y}$ & $\mathrm{Z}$ \\
\hline $\begin{array}{l}\text { Ponto } \\
1\end{array}$ & R01 & \multirow{4}{*}{$\begin{array}{c}\text { Argissolo Vermelho- } \\
\text { Amarelo }\end{array}$} & \multirow{4}{*}{ PVAe } & 0503186 & 8654838 & 243 \\
\hline $\begin{array}{l}\text { Ponto } \\
2\end{array}$ & R02 & & & 0503286 & 8654894 & 249 \\
\hline $\begin{array}{l}\text { Ponto } \\
3\end{array}$ & R03 & & & 0506611 & 8655676 & 227 \\
\hline $\begin{array}{l}\text { Ponto } \\
4\end{array}$ & R04 & & & 0506586 & 8655676 & 237 \\
\hline $\begin{array}{l}\text { Ponto } \\
5\end{array}$ & R05 & Planossolo Háplico & SXen & 0508880 & 8644662 & 221 \\
\hline
\end{tabular}

Os dados tabulados com as composições mineralógicas podem ser observados na tabela 2 .

Tabela 2. Dados tabulados com as composições mineralógicas

\begin{tabular}{|l|l|l|l|}
\hline Pontos & $\begin{array}{l}\text { Nome da } \\
\text { amostra }\end{array}$ & $\begin{array}{l}\text { Composição mineralógica } \\
\text { (resultado TSG) }\end{array}$ & $\begin{array}{l}\text { Composição mineralógica } \\
\text { (análise visual) }\end{array}$ \\
\hline $\begin{array}{l}\text { Ponto } \\
1\end{array}$ & R01 & $\begin{array}{l}\text { Caulinita, montmorilonita e } \\
\text { goethita }\end{array}$ & $\begin{array}{l}\text { Caulinita, montmorilonita e } \\
\text { goethita }\end{array}$ \\
\hline $\begin{array}{l}\text { Ponto } \\
2\end{array}$ & R02 & Caulinita, muscovita e nacrita & Caulinita e goethita \\
\hline $\begin{array}{l}\text { Ponto } \\
3\end{array}$ & R03 & Caulinita e montmorilonita & Caulinita e montmorilonita \\
\hline $\begin{array}{l}\text { Ponto } \\
4\end{array}$ & R04 & Caulinita e montmorilonita & Caulinita e montmorilonita \\
\hline $\begin{array}{l}\text { Ponto } \\
5\end{array}$ & R05 & Caulinita e montmorilonita & Caulinita e montmorilonita \\
\hline
\end{tabular}
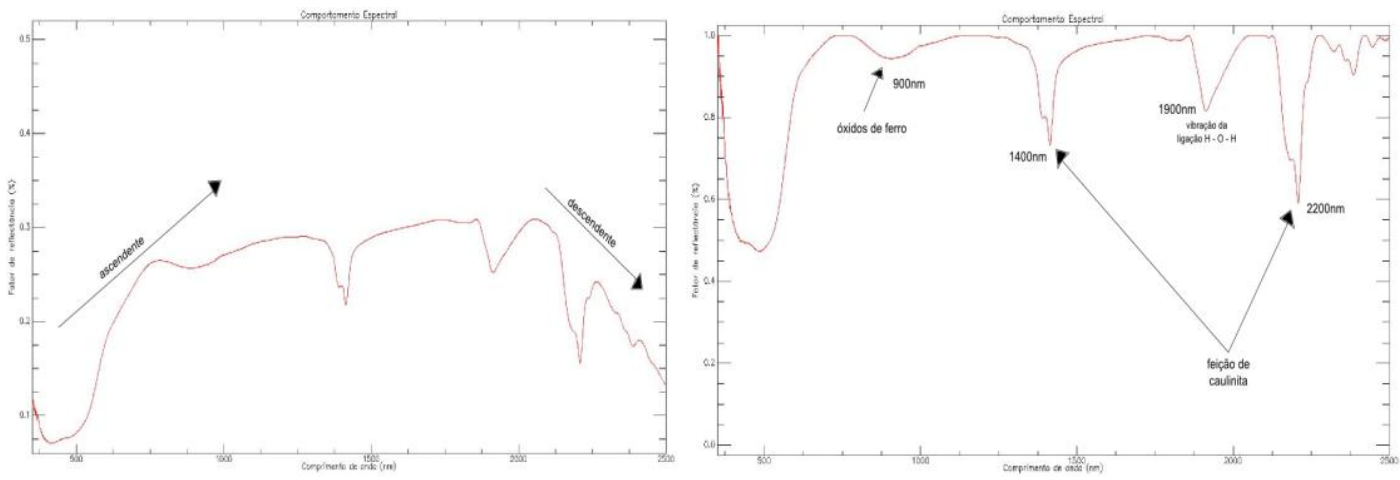

Figura 2. Comportamento espectral da amostra do ponto 2

Nos pontos 1, 3, 4 5, a feição de absorção em $1900 \mathrm{~nm}$ indica a presença de água constitucional (Madeira Netto \& Baptista, 2000). Esta banda corresponde às vibrações moleculares dos grupos químicos presentes nos minerais, são compatíveis com o solo argissolo e planossolo, e são típicas da presença de montmorilonita, que tem composição química mínima dada por $\mathrm{R}_{0,33}{ }^{+}\left(\mathrm{A}_{1,67} \mathrm{Mg}_{0,33}\right) \mathrm{Si}_{4} \mathrm{O}_{10}(\mathrm{OH})_{2}$. No ponto 2 
como não se detectou presença de montmorilonita, a feição de absorção em 1900nm indica a presença de água absorvida e não água constitucional (EPIPHANIO, 1992).

Nos pontos 1 e 2 observou-se a presença de goethita $(\alpha-\mathrm{FeOOH})$ que é o mineral mais comum dos óxidos de ferro, ocorrendo em praticamente todos os ambientes pedogênicos e muito utilizado nas indústrias. Os óxidos de ferro são considerados o segundo grupo mais importante de minerais da fração argila. Suas propriedades químicas os tornam excelentes minerais para a recuperação de áreas degradas por contaminação natural ou antrópica de solos (COSTA\&BIGHAN, 2009).

O programa TSG indicou a presença de alguns minerais (nacrita e muscovita) que não foram identificados na análise visual, e esta identificou minerais que não foram indicados pelo software. Essa divergência pode ser devido ao fato de que os espectros obtidos da biblioteca espectral da United States Geological Survey (USGS) são de minerais puros, já as amostras de solo possuem diversos minerais e outros constituintes em diferentes proporções, o que acaba gerando erros que podem ser aceitáveis ou não, fazendo-se necessárias investigações mais aprofundadas dos espectros (JESUS et al., 2013).

\section{CONSIDERAÇÕES FINAIS}

O desenvolvimento deste trabalho permitiu a geração de espectro de solos da região de Feira de Santana para a Biblioteca espectral do Laboratório de Espectrorradiometria do PPGM. As curvas espectrais foram devidamente caracterizadas e seu comportamento foi amplamente discutido visando entender melhor as características mineralógicas dos solos. Desta forma, contribuindo para a diminuição da carência de bibliotecas espectrais de solo propriamente dito, o que prova a importância de mais trabalhos ligados a espectrorradiometria de solos

\section{REFERÊNCIAS}

BELLINASO, H. Biblioteca espectral de solos e sua aplicação na quantificação de atributos e classificação. Dissertação (Mestrado em Agronomia) - Escola superior de Agricultura Luis de Queiroz, Piracicaba. 2009

CLARK, R. N., Chapter. 1999. Spectroscopy of Rocks and Minerals, and Principles of Spectroscopy, in Manual of Remote Sensing, Volume 3, Remote Sensing for the Earth Sciences, (A.N. Rencz, ed.) John Wileyand Sons, New York, p 3- 58. Disponível em: http://www.clarkvision.com/rnc/publist.html. Acesso em: janeiro 2010.

COSTA, A.C.S. \& BIGHAM, J.M. In: MELO, V.F. \& ALLEONI, L.R.F., eds. Química e mineralogia do solo; Conceitos básicos. Parte 1. Viçosa, MG, Sociedade Brasileira de Ciênciado Solo, 2009. p.506-520.

EPIPHANIO, J.C.N.; FORMAGGIO, A.R.; VALERIANO, M.M.; OLIVEIRA, J.B. Comportamento espectral de solos do Estado de São Paulo. São José dos Campos: INPE, 1992. 131p. (INPE-5424- PRP-172).

JESUS, T.B. et al. Caracterização granulométrica e mineralógica dos sedimentos como suporte para análise de contaminação ambiental em nascentes do rio Subaé, Feira de Santana (BA). Geochimica Brasiliensis 27(1): p.49-62, 2013.

MADEIRA NETTO, J.S.; BAPTISTA, G.M.M. Reflectância espectral de solos. Planaltina:EMBRAPA Cerrados, 2000. 55p.

SATO, M.V. Primeira aproximação da biblioteca espectral de solos do Brasil: caracterização de espectros de solos e quantificação de atributos. Piracicaba, 2015. $102 p$

SANTOS, R.O.; CHAVES, J.M.; OLIVEIRA, T.M.; SILVA, T.B.;Contribuição para abiblioteca espectral de solos da região sisaleira.XX Seminário de Iniciação Científica da UEFS. Feira de Santana. 2016. 